University of Nebraska - Lincoln

DigitalCommons@University of Nebraska - Lincoln

Faculty Publications in Food Science and Technology

2019

In vitro bioaccessibility of novel low-crystallinity phytosterol nanoparticles in non-fat and regular-fat foods

Ali Ubeyitogullari

Ozan Ciftci

Follow this and additional works at: https://digitalcommons.unl.edu/foodsciefacpub

Part of the Food Science Commons

This Article is brought to you for free and open access by the Food Science and Technology Department at DigitalCommons@University of Nebraska - Lincoln. It has been accepted for inclusion in Faculty Publications in Food Science and Technology by an authorized administrator of DigitalCommons@University of Nebraska Lincoln. 


\title{
In vitro bioaccessibility of novel low-crystallinity phytosterol nanoparticles in non-fat and regular-fat foods
}

\author{
Ali Ubeyitogullari and Ozan N. Ciftci \\ Department of Food Science and Technology, University of Nebraska-Lincoln, \\ Lincoln, NE 68588-6205, USA \\ Corresponding author — 0. N. Ciftci, email ciftci@unl.edu
}

\begin{abstract}
Crystalline structure of phytosterols leads to poor bioavailability and makes their incorporation into foods challenging. Bioaccessibility of first-of-their-kind low-crystallinity phytosterol nanoparticles impregnated in nanoporous starch aerogels (PSNSA) was evaluated in non-, low-, and regular-fat solid and aqueous food formulations, namely, granola bars and puddings for the first time. Bioaccessibility of the phytosterol nanoparticles was significantly higher than that of crude phytosterols in all food formulations $(p<.05)$; it was 88.2 and $91.8 \%$ for low- or regular-fat granola bars, respectively, whereas bioaccessibility of crude phytosterols was ca. $30 \%$ in those formulations. However, decreasing the lipid content to zero resulted in lower phytosterols' bioaccessibilities from both PS-NSA (53\%) and crude phytosterols (ca. 16\%) in non-fat granola bars. Bioaccessibility of crude phytosterols (2\%) was significantly enhanced with PS-NSA (19\%) in the pudding formulation. PS-NSA allows preparation of low- and non-fat foods enriched with phytosterols while enhancing the health benefits of phytosterols with smaller doses.
\end{abstract}

Keywords: Aerogel, Phytosterol, Supercritical, Starch, Nanoparticles, Bioavailability

Published in Food Research International 123 (2019), pp 27-35.

doi 10.1016/j.foodres.2019.04.014

Copyright (C) 2019 Elsevier Ltd. Used by permission.

Submitted 19 November 2018; revised 5 April 2019; accepted 6 April 2019; published 8 April 2019. 


\section{Introduction}

In recent years, the food industry has placed a high priority on the development of health and wellness improving foods that use bioactive compounds. Among those bioactive compounds, phytosterols received much attention due to their LDL-cholesterol lowering properties (Demonty et al., 2009; Ras, Geleijnse, \& Trautwein, 2014). In addition, phytosterols exhibit anticancer (Shahzad et al., 2017; Woyengo, Ramprasath, \& Jones, 2009) and anti-inflammatory (Aldini et al., 2014) properties.

According to a recent meta-analysis by Ras et al. (2014), consumption of 0.6-3.3 g phytosterols/day can reduce LDL-cholesterol by 6-12\%. Furthermore, the U.S. Food and Drug Administration (FDA) authorized the use of health claims related to the daily intake of plant sterol/stanol esters and reduced risk of coronary heart disease (CHD) in 2000 by an interim final rule (IFR) (21 CFR 101.83) (FDA, 2000). The health claim specifies that "foods containing at least $0.65 \mathrm{~g}$ per serving of plant sterol esters (or $1.7 \mathrm{~g}$ of plant stanol esters), eaten twice a day with meals for a daily total intake of at least $1.3 \mathrm{~g}$ (or $3.4 \mathrm{~g}$ of stanol esters), as part of a diet low in saturated fat and cholesterol, may reduce the risk of heart disease". In 2010, FDA proposed to amend the IFR by including the use of the health claim on foods containing nonesterified phytosterols and increasing the daily dietary intake of phytosterols to $2 \mathrm{~g}$ (FDA, 2010). Likewise, European Food Safety Authority (EFSA) authorized a health claim on the relationship between the intake of $3 \mathrm{~g} /$ day plant sterols/stanols and lowering blood cholesterol and reducing risk of CHD (EFSA, 2012).

Since a typical Western diet naturally contains low amount of phytosterols (150-400 mg/day), phytosterols need to be incorporated into foods to get the potential health benefits. However, incorporating phytosterols into foods possesses several technological challenges due to their high melting point crystalline structure making phytosterols insoluble in water and poorly soluble in fats and oils (Moreno-Calvo et al., 2014). Therefore, preparing low- or non-fat foods-enriched with crude phytosterols is still a major challenge. Crystallization of phytosterols in foods leads to a sandy texture which adversely affects sensory attributes and consumer acceptability. The current approach to overcome this problem is to esterify phytosterols to obtain phytosterol esters which are semisolid at room conditions and can be incorporated into high-fat foods like margarine and vegetable oil spreads (Panpipat, Chaijan, \& Guo, 2018). 
In addition to technological challenges associated with incorporating crude phytosterols into low- and non-fat foods, bioavailability of phytosterols is very low (0.5-2\%) (Rysz, Franczyk, Olszewski, Banach, \& Gluba-Brzozka, 2017) due to their crystalline structure and poor water solubility. There have been considerable research efforts to enhance the water solubility and/or bioavailability of phytosterols. These include emulsion formulations (Fisher, Wachtel, Aserin, \& Garti, 2013; Zychowski et al., 2016), colloidal particle formation by antisolvent precipitation (Kawachi, Tanaka, Hirano, Igarashi, \& Ooshima, 2006; Rossi, Seijen ten Hoorn, Melnikov, \& Velikov, 2010), microencapsulation by spray drying (Di Battista, Constenla, Ramírez-Rigo, \& Piña, 2015; Tolve, Condelli, Can, \& Tchuenbou-Magaia, 2018), and chemo-enzymatic modifications (He, Zhu, \& Chen, 2018). However, there are some drawbacks associated with these techniques such as the use of toxic organic solvents, limited number of food-grade ingredients and formation of undesirable off-flavors due to the presence of surfactants.

Supercritical carbon dioxide $\left(\mathrm{SC}-\mathrm{CO}_{2}\right)$ technology has been used as a green method for the isolation of phytosterols from various sources (Uddin et al., 2014); however, the use of supercritical fluid technologies for particle engineering is new. Recently, a novel green nanomanufacturing approach that utilizes nanoporous starch aerogels (NSAs) in conjunction with $\mathrm{SC}-\mathrm{CO}_{2}$ to form first-of-their-kind low-crystallinity phytosterol nanoparticles was introduced by our group (Ubeyitogullari \& Ciftci, 2016b, 2017). NSAs were produced from wheat starch with a surface area of $60 \mathrm{~m}^{2} / \mathrm{g}$, pore size of $20 \mathrm{~nm}$ and density of $0.12 \mathrm{~g} /$ $\mathrm{cm}^{3}$ (Ubeyitogullari \& Ciftci, 2016a). Afterwards, low-crystallinity phytosterol nanoparticles were generated by impregnation of phytosterols into nanopores of the NSA using SC- $\mathrm{CO}_{2}$ (Ubeyitogullari \& Ciftci, $2016 \mathrm{~b}, 2017)$. This new method provides a better control over the particle size, morphology and crystallinity, does not use any solvents, and overcomes agglomeration problem of the previous $\mathrm{SC}-\mathrm{CO}_{2}$-based techniques (Moreno-Calvo et al., 2014; Türk \& Lietzow, 2004, 2008; Türk, Upper, \& Hils, 2006). Very recently, we have shown that the low-crystallinity phytosterol nanoparticles exhibited 37-fold higher water solubility than crude phytosterols (Ubeyitogullari \& Ciftci, 2016b), and bioaccessibility was improved by 20 -fold with this approach (Ubeyitogullari, Moreau, Rose, Zhang, \& Ciftci, 2018).

In this study, the bioaccessibility of the novel low-crystallinity phytosterol nanoparticles were tested in a real food system for the first 
time. Although phytosterols were recently incorporated into several food products such as margarine (Lin et al., 2018; Panpipat et al., 2018; Rudzińska, Przybylski, \& Wąsowicz, 2014), yogurt (Comunian et al., 2017), milk-based fruit beverages (Alvarez-Sala et al., 2016; López- García, Cilla, Barberá, \& Alegría, 2017), dark chocolate (Botelho et al., 2014), and cream cheese (Ningtyas, Bhandari, Bansal, \& Prakash, 2018), the aim of these studies was to prepare functional foods with phytosterols as ingredient focusing on the stability, sensory quality and texture of the products. However, to the best of our knowledge, none of the above-mentioned water solubility and/or bioaccessibility improvement approaches were tested in a 'real' food application. Even though our previous studies showed that the in vitro bioaccessibility of the low-crystallinity phytosterol nanoparticles was increased, the performance of those particles in real food formulations is not known. There is a critical need to test the performance of the PS-NSA in a food formulation, especially non-fat foods, since the food matrix and/or food production process might affect the bioaccessibility and stability of the novel low-crystallinity phytosterol nanoparticles.

Therefore, the main objective of this study was to investigate the performance of the PS-NSA in low-, regular-, and non-fat solid and soft food preparations, and determine the effect of food matrix on the bioaccessibility of the PS-NSA. The specific objectives were to: (a) form PS-NSA via SC- $\mathrm{CO}_{2}$ impregnation of phytosterols into NSA, (b) produce PS-NSAenriched regular-, low- and non-fat granola bars and PS-NSA-enriched non-fat puddings, (c) characterize the PS-NSA-enriched functional foods for their morphology and texture, and (d) determine the bioaccessibility of the low crystallinity phytosterol nanoparticles in the granola bars and puddings using a simulated digestion.

\section{Materials and methods}

\subsection{Materials}

Native and pregelatinized wheat starches (25\% amylose and 75\% amylopectin) were kindly provided by Manildra Milling Corporation (IA, USA). Ethanol (100\%) was purchased from Decon Laboratories, Inc. (PA, USA), and liquid carbon dioxide (99.99\% purity) was obtained from 
Matheson Tri-Gas, Inc. (NE, USA). Crude phytosterols were purchased from MP Biomedicals ( $\mathrm{OH}, \mathrm{USA})$ and their composition was determined using gas chromatography-mass spectrometry (GC-MS) as 52.9 $\pm 0.3 \% \beta$-sitosterol, $22.4 \pm 0.3 \%$ stigmasterol, and $24.7 \pm 0.4 \%$ campesterol (Ubeyitogullari \& Ciftci, 2016b). Silylation reagent Sylon BFT [N,Obis(trimethylsilyl)trifluoroacetamide (BSTFA):trimethylchlorosilane (TMCS), 99:1] was purchased from Supelco Inc. (PA, USA), while pyridine was obtained from EMD Chemicals, Inc. (NJ, USA). The internal standard, $5 \alpha$-cholestane (> 98\%) was acquired from Acros Organics (NJ, USA). Granulated sugar, skim milk, vanilla extract, salt, oats, shredded coconut, sliced almonds, baking soda, honey, refined canola oil, nonfat dry milk powder and egg whites were all purchased from a local grocery store. The other granola bar and pudding ingredients, namely, dextrose, food grade tetrasodium pyrophosphate and disodium phosphate, and gum arabic were obtained from Now Foods (IL, USA), Innophos (NJ, USA) and TIC Gums (MD, USA), respectively.

Alpha-amylase from Bacillus subtilis (160,000 BAU/g) was purchased from MP Biomedicals (OH, USA). Amano lipase A from fungus Aspergillus niger (132,000 U/g) was kindly supplied by Amano Enzyme Inc. (IL, USA). Pepsin from porcine gastric mucosa (3616 U/mg protein), pancreatin from porcine pancreas (neutral protease: 208 USP U/ mg solid; $\alpha$-Amylase: $223 \mathrm{U} / \mathrm{mg}$ solid; lipase: $38.5 \mathrm{USP} \mathrm{U} / \mathrm{mg}$ solid), lipase from porcine pancreas (419 U/mg protein), and bile extract from porcine were purchased from Sigma-Aldrich (MO, USA). All other chemicals were of analytical grade.

\subsection{Nanoporous starch aerogel (NSA) formation}

NSA was produced from wheat starch using previously optimized processing conditions for the highest surface area (Ubeyitogullari \& Ciftci, 2016a). Briefly, wheat starch (10 wt\%) was first processed at $120^{\circ} \mathrm{C}$ and $600 \mathrm{rpm}$ for $20 \mathrm{~min}$ in a closed high-pressure reactor (4520 Bench Top Reactor, Parr Instrument Company, IL, USA) to obtain a hydrogel. Then, the hydrogels were retrograded at $4{ }^{\circ} \mathrm{C}$ for $48 \mathrm{~h}$. After retrogradation, hydrogels were subjected to a five-step solvent exchange $(30,50,70$, and $100 \%(\mathrm{v} / \mathrm{v})$ ethanol for $1 \mathrm{~h}$ residence time then 100\% ethanol for $24 \mathrm{~h}$ ) to replace the water in the hydrogels with ethanol to obtain an alcogel. Finally, NSAs were obtained by SC-CO ${ }_{2}$ drying of the alcogels at $10 \mathrm{MPa}$ 
and $40{ }^{\circ} \mathrm{C}$ for $4 \mathrm{~h}$ with a $\mathrm{CO}_{2}$ flow rate of $0.5 \mathrm{~L} / \mathrm{min}$ (measured at ambient conditions). NSAs were characterized according to the methods of Ubeyitogullari and Ciftci (2016a).

\subsection{Formation of low-crystallinity phytosterol nanoparticles}

Phytosterols were impregnated into the NSAs using the previously optimized impregnation conditions for the highest phytosterol bioaccessibility and impregnation capacity (Ubeyitogullari \& Ciftci, 2017; Ubeyitogullari, Moreau, et al., 2018). The details of the laboratory scale SC- $\mathrm{CO}_{2}$ impregnation system were described elsewhere (Ubeyitogullari \& Ciftci, 2017). Briefly, NSA monoliths (1 g) and crude phytosterols (0.5 g) were separately wrapped in filter papers (Whatman \#41) and placed in bottom and top compartments of the high pressure vessel. First, the system was heated to $90^{\circ} \mathrm{C}$ and then pressurized with $\mathrm{CO}_{2}$ to $45 \mathrm{MPa}$ using a double head high pressure syringe pump (Model 260D, Teledyne Isco Inc., NE, USA). SC- $\mathrm{CO}_{2}$ impregnation was carried out by a semi-dynamic mode where the $\mathrm{CO}_{2}$ flow rate was adjusted to $1 \mathrm{~L} / \mathrm{min}$ (measured at ambient conditions) by opening the shut-off valve every 10 min for $1 \mathrm{~min}$. At the end of $1 \mathrm{~h}$ impregnation, the system was cooled down to $25^{\circ} \mathrm{C}$ at a cooling rate of $10{ }^{\circ} \mathrm{C} / \mathrm{min}$ by blowing $\mathrm{CO}_{2}$ to the vessel from a compressed liquid $\mathrm{CO}_{2}$ cylinder $(6 \mathrm{MPa})$. Afterwards, the system was depressurized to atmospheric pressure at a $\mathrm{CO}_{2}$ flow rate of 1 $\mathrm{L} /$ min (measured at ambient conditions). This impregnation cycle was repeated three times to improve the impregnation capacity and particle size distribution as described in detail previously (Ubeyitogullari \& Ciftci, 2017). Finally, PS-NSA was collected and stored at $-20^{\circ} \mathrm{C}$ until further use.

\subsection{Determination of $\mathrm{SC}-\mathrm{CO}_{2}$ impregnation capacity}

First, phytosterols were extracted from $0.15 \mathrm{~g}$ of PS-NSA using $5 \mathrm{~mL}$ of chloroform with occasional vortexing for $1 \mathrm{~h}$. Then, the mixture was filtered through a syringe filter with a pore-size of $0.45 \mu \mathrm{m}$. Filter cake was washed with $5 \mathrm{~mL}$ of chloroform three times. Lastly, all the filtrate was dried under a nitrogen stream at room temperature $\left(21^{\circ} \mathrm{C}\right)$ and the phytosterols in the dry residue were quantified using a GC as described in Section 2.9. Impregnation capacity was reported as mg phytosterols/g PS-NSA. All the experiments were carried out in triplicate. 


\subsection{Preparation of granola bars and puddings}

Granola bars were prepared according to Aigster, Duncan, Conforti, and Barbeau (2011) with minor modifications where the waxy corn starch was replaced with pregelatinized wheat starch as NSA was produced from wheat starch. Granola bar formulations are provided in Table 1. PS-NSA amount was determined based on the impregnation capacity to supply $1 \mathrm{~g}$ of phytosterols. To prepare the granola bars, the dry ingredients (oats, PS-NSA, coconut, almonds, baking soda and gum arabic) were mixed with the liquid ingredients (honey, canola oil, egg whites and vanilla extract). Then, the mixture was baked in an oven at $163^{\circ} \mathrm{C}$ for 35 min. After cooling at room temperature $\left(21^{\circ} \mathrm{C}\right)$, the products were cut to obtain two granola bars (dimensions: $10 \times 4 \times 1 \mathrm{~cm}$ ) from each batch. The granola bars were individually packed and stored at room temperature until characterized.

Granola bar formulations with the same ingredients except canola oil were prepared to produce low-fat granola bars. Water was used instead of canola oil to help the dispersion of starch in the formulations. The non-fat granola bars were prepared using the same ingredients as

Table 1. Granola bar formulations.

\begin{tabular}{|c|c|c|c|c|c|c|}
\hline \multirow[t]{3}{*}{ Ingredients } & \multicolumn{6}{|c|}{ Weight per batch $(g)$} \\
\hline & \multicolumn{3}{|c|}{ Regular-fat } & \multicolumn{3}{|l|}{ Low-fat } \\
\hline & $P S-N S A$ & $\begin{array}{l}\text { Crude PS } \\
\text { +empty } \\
\text { starch }\end{array}$ & $\begin{array}{l}\text { Crude PS } \\
+N S A \\
\text { pregel }\end{array}$ & $P S-N S A$ & $\begin{array}{l}\text { Crude PS } \\
\text { +empty } \\
\text { starch }\end{array}$ & $\begin{array}{l}\text { Crude PS } \\
+N S A \\
\text { pregel }\end{array}$ \\
\hline Oats & 22.5 & 22.5 & 22.5 & 22.5 & 22.5 & 22.5 \\
\hline Crude PS & 0.0 & 1.0 & 1.0 & 0.0 & 1.0 & 1.0 \\
\hline Empty NSA & 2.4 & 12.4 & 0.0 & 2.4 & 12.4 & 0.0 \\
\hline PS-NSA & 11.0 & 0.0 & 0.0 & 11.0 & 0.0 & 0.0 \\
\hline Pregel starch & 0.0 & 0.0 & 12.4 & 0.0 & 0.0 & 12.4 \\
\hline Shredded coconut & 4.4 & 4.4 & 4.4 & 4.4 & 4.4 & 4.4 \\
\hline Almonds & 5.6 & 5.6 & 5.6 & 5.6 & 5.6 & 5.6 \\
\hline Baking soda & 0.6 & 0.6 & 0.6 & 0.6 & 0.6 & 0.6 \\
\hline Honey & 20.8 & 20.8 & 20.8 & 20.8 & 20.8 & 20.8 \\
\hline Canola oil & 14.5 & 14.5 & 14.5 & 0.0 & 0.0 & 0.0 \\
\hline Water & 0.0 & 0.0 & 0.0 & 14.5 & 14.5 & 14.5 \\
\hline Egg whites & 2.8 & 2.8 & 2.8 & 2.8 & 2.8 & 2.8 \\
\hline Vanilla extract & 0.6 & 0.6 & 0.6 & 0.6 & 0.6 & 0.6 \\
\hline Gum arabic & 1.3 & 1.3 & 1.3 & 1.3 & 1.3 & 1.3 \\
\hline
\end{tabular}


in the low-fat granola bars, but the ingredients were defatted by Folch extraction (Folch, Lees, \& Stanley, 1957) to remove all the lipids naturally present in the ingredients. Phytosterols in the separated lipids were quantified by GC as described in Section 2.9.

Dry ingredients of pudding formulations are given in Table 2. Puddings were prepared by mixing the dry ingredients (sugar, PS-NSA, dextrose, nonfat dry milk, tetrasodium pyrophosphate, disodium phosphate, vanilla powder and salt) with $225 \mathrm{~mL}$ of skim milk. Then, the mixture was beaten with a wire whisk for $2 \mathrm{~min}$ and placed in tightly-sealed plastic storage containers at $4{ }^{\circ} \mathrm{C}$. The physical mixture of crude phytosterols with pregelatinized starch (crude PS+pregel starch) or empty NSA (crude PS+empty NSA) was used instead of PSNSA as control for both granola bar and pudding formulations.

\subsection{Morphology}

The morphology of the phytosterol nanoparticles in the NSA matrix was observed by a field emission scanning electron microscope (S4700 FESEM, Hitachi, Tokyo, Japan). The FE-SEM was operated at $5 \mathrm{kV}$ and $15 \mathrm{~mA}$ under low vacuum mode. The specimens were placed on aluminum SEM stubs with double-side conductive carbon tape and sputter-coated with a chromium layer (Desk V HP TSC, Denton Vacuum LLC, NJ, USA) before the SEM analysis. Particle size of the phytosterol nanoparticles were determined from the SEM images using ImageJ v. 1.50i software (public domain, National Institutes of Health, USA) (Ubeyitogullari \& Ciftci, 2017).

Table 2. Pudding formulations.

\begin{tabular}{llcc} 
Ingredients & \multicolumn{2}{l}{ Weight (g) per batch } & \\
& PS-NSA & Crude PS+empty NSA & Crude PS+pregel starch \\
\hline Sugar & 33.3 & 33.3 & 33.3 \\
Crude PS & 0.0 & 1.0 & 1.0 \\
Empty NSA & 0.0 & 10.0 & 0.0 \\
PS-NSA & 11.0 & 0.0 & 0.0 \\
Pregel starch & 0.0 & 0.0 & 10.0 \\
Dextrose & 3.0 & 3.0 & 3.0 \\
Nonfat dry milk & 1.0 & 1.0 & 1.0 \\
Tetrasodium pyrophosphate & 0.7 & 0.7 & 0.7 \\
Disodium phosphate & 0.5 & 0.5 & 0.5 \\
Vanilla powder & 0.1 & 0.1 & 0.1 \\
Salt & 0.5 & 0.5 & 0.5 \\
\hline
\end{tabular}


Morphology of puddings was examined using an inverted fluorescence microscope (EVOS® FL Auto Cell Imaging System, Life Technologies, CA, USA). An aliquot of sample $(10 \mu \mathrm{L})$ was placed on a glass microscope slide and covered with a cover slip prior to analysis. The images were captured with a color camera using a $10 \times$ objective.

\subsection{Texture analysis}

Hardness of the granola bars was measured by a texture analyzer (TAXT2, Stable Micro Systems, Surrey, UK) according to Aigster et al. (2011). The texture analyzer was equipped with a $30 \mathrm{~kg}$ load cell, and operated with a three-point bend rig and a knife-edge probe. The load cell was calibrated with a $2 \mathrm{~kg}$ calibration weight prior to the analysis. The granola bars were placed at the center of three-point bend attachment where the distance between the supporting points was $5 \mathrm{~cm}$. Granola bars were compressed with a test speed of $2 \mathrm{~mm} / \mathrm{s}$ to a distance of 10 $\mathrm{mm}$. Hardness was determined as the maximum force (g) during the compression test.

The texture analysis of the puddings was performed according to Thaiudom and Pracham (2018). Hardness, adhesiveness, springiness, cohesiveness, and gumminess of the puddings were determined using the same texture analyzer in a texture profile analysis (TPA) mode at room temperature $\left(21^{\circ} \mathrm{C}\right)$. The measurements were carried out with a $25-\mathrm{mm}$ diameter cylinder probe at a test speed of $2 \mathrm{~mm} / \mathrm{s}$ and $60 \%$ strain with a $5 \mathrm{~s}$ of waiting time. Five measurements were conducted for each treatment.

\subsection{Simulated digestion}

A sequential oral, gastric, and intestinal digestion was carried out according to Ubeyitogullari, Moreau, et al. (2018). Simulated salivary fluid (SSF), simulated gastric fluid (SGF), and simulated intestinal fluid (SIF) were prepared according to Minekus et al. (2014), except that the enzyme amounts were determined according to the enzyme activities reported by the manufacturers rather than experimentally determined. All the enzyme solutions were made up in their corresponding phase electrolyte stock solutions (SSF, SGF or SIF). Simulated digestion of the granola bars and puddings were performed in triplicate. The physical mixture of crude PS with empty NSA or pregelatinized starch was used as control. 


\subsubsection{Simulated oral digestion}

Before simulated digestion, granola bars were ground to simulate mastication and then passed through a sieve \#7 with an opening size of 2.8 mm (Jalabert-Malbos, Mishellany-Dutour, Woda, \& Peyron, 2007), whereas puddings were used without any treatment. First, SSF electrolyte stock solution $(3.5 \mathrm{~mL})$ was mixed with the sample $(1 \mathrm{~g})$ in a $50 \mathrm{~mL}$ Erlenmeyer flask. Then, $0.5 \mathrm{~mL}$ of $\alpha$-amylase solution $(750 \mathrm{U} / \mathrm{mL})$ was included to achieve an $\alpha$-amylase concentration of $67 \mathrm{U} / \mathrm{mL}$ in the final oral phase mixture. Subsequently, deionized water $(0.975 \mathrm{~mL})$ and $0.3 \mathrm{M}$ $\mathrm{CaCl}_{2}(25 \mu \mathrm{L})$ were added into the flask and the $\mathrm{pH}$ was adjusted to 7.0. Lastly, the mixture was incubated in a shaking water bath (Barnstead/ Lab-Line MaxQ $\mathrm{Q}^{\text {TM }} 7000$, Barnstead International, IA, USA) at $37^{\circ} \mathrm{C}$ and $150 \mathrm{rpm}$ for $30 \mathrm{~s}$.

\subsubsection{Simulated gastric digestion}

After the oral digestion, SGF electrolyte stock solution (3.25 mL, pH 3) was added onto the oral bolus and then the $\mathrm{pH}$ was decreased to 3.0 using $1 \mathrm{M} \mathrm{HCl}$ solution $(75 \mu \mathrm{L})$. After the $\mathrm{pH}$ adjustment, $0.5 \mathrm{~mL}$ of porcine pepsin $(40,000 \mathrm{U} / \mathrm{mL})$ and $0.25 \mathrm{~mL}$ of fungal lipase $(1000 \mathrm{U} / \mathrm{mL})$ solutions were added into the flask. Then, $2.5 \mu \mathrm{L}$ of $0.3 \mathrm{M} \mathrm{CaCl}_{2}$ solution and $0.923 \mathrm{~mL}$ of deionized water were included. Hence, a final ratio of oral bolus to SGF of ca. 50:50 (v/v) was obtained. Lastly, the mixture was incubated in a shaking water bath at $37^{\circ} \mathrm{C}$ and $100 \mathrm{rpm}$ for $2 \mathrm{~h}$. The pH was adjusted to 3.0 throughout the gastric digestion.

\subsubsection{Simulated intestinal digestion}

Following the gastric digestion, $6.125 \mathrm{~mL}$ of SIF electrolyte stock solution was mixed with the gastric chyme. Then, the $\mathrm{pH}$ was adjusted to $7.0 \mathrm{us-}$ ing $30 \mu \mathrm{L}$ of $1 \mathrm{M} \mathrm{NaOH}$ solution. The amount of pancreatin was calculated based on the $\alpha$-amylase activity to achieve a final $\alpha$-amylase activity of $194 \mathrm{U} / \mathrm{mL}$ and hence, $1.25 \mathrm{~mL}$ of pancreatin solution (3200 U/mL) was prepared. Then, 39,310 $\mathrm{U}$ of porcine pancreatic lipase was added into the pancreatin solution to provide a final lipase activity of $1942 \mathrm{U} / \mathrm{mL}$. Afterwards, $0.625 \mathrm{~mL}$ of $320 \mathrm{mM}$ fresh bile solution (prepared in SIF), $20 \mu \mathrm{L}$ of $0.3 \mathrm{M} \mathrm{CaCl}_{2}$ and $1.95 \mathrm{~mL}$ deionized water were included into the flask. The final ratio of gastric chyme to SIF was ca. 50:50 (v/v). Lastly, the mixture was placed in the shaking water bath at $37^{\circ} \mathrm{C}$ and $100 \mathrm{rpm}$ for $2 \mathrm{~h}$. The $\mathrm{pH}$ of the mixture was monitored throughout the intestinal digestion and kept at $\mathrm{pH} 7.0 \mathrm{using} 1 \mathrm{M} \mathrm{HCl}$ or $1 \mathrm{M} \mathrm{NaOH}$ solutions. 


\subsubsection{Bioaccessible fraction}

The bioaccessible fraction (micellar phase) was obtained by centrifugation of the digested samples at $10,000 \mathrm{~g}$ and $4{ }^{\circ} \mathrm{C}$ for $30 \mathrm{~min}$ (Sorvall ${ }^{\mathrm{TM}}$ Legend ${ }^{\mathrm{TM}} \mathrm{X} 1 \mathrm{R}$, Thermo Scientific, Osterode am Harz, Germany) (Cao, Ou, Lin, \& Tang, 2016). The bioaccessibility (\%) of the phytosterols in the products was calculated using the following formula:

$$
\text { Bioaccessibility }(\%)=\frac{\begin{array}{l}
\text { Weight of the phytosterols } \\
\text { in the bioaccessible fraction }
\end{array}}{\text { Weight of the total phytosterols included }} \times 100
$$

\subsection{Phytosterol analysis}

Phytosterols in the samples (PS-NSA, granola bars, puddings, separated lipids, and bioaccessible fractions) were quantified by a Hewlett- Packard (HP) 6890 GC (Agilent Technologies, DE, USA) equipped with a flame ionization detector according to the method of Ubeyitogullari and Ciftci (2017). Briefly, $50 \mu \mathrm{L}$ of $5 \alpha$-cholestane $(2.25 \mathrm{mg} / \mathrm{mL})$ was added onto the sample and the mixture was subjected to saponification with $4 \mathrm{~mL}$ of $1 \mathrm{M} \mathrm{KOH}$ in methanol at $40^{\circ} \mathrm{C}$ for $1 \mathrm{~h}$. Then, the mixture was kept at room temperature $\left(21^{\circ} \mathrm{C}\right)$ for $18 \mathrm{~h}$. After saponification, $2 \mathrm{~mL}$ of deionized water was added and vortexed for $10 \mathrm{~s}$. Next, the unsaponifiable fraction was extracted with $5 \mathrm{~mL}$ of hexane/methyl tertbutyl ether mixture $(50,50, v / v)$ for three times with occasional vortexing. The total extract was dried by blowing nitrogen at room temperature $\left(21^{\circ} \mathrm{C}\right)$.

Dry residues were dissolved in $0.3 \mathrm{~mL}$ of pyridine and subjected to silylation with $1 \mathrm{~mL}$ of Sylon BFT at $50^{\circ} \mathrm{C}$ for $30 \mathrm{~min}$. The silylated samples were injected onto a DB-35MS GC column $(25 \times 0.20 \mathrm{~mm} \times 0.33 \mu \mathrm{m}$, J\&W, Agilent Technologies, CA, USA) with an HP G1512A autosampler. The injector was operated in a splitless mode. Helium with a flow rate of $0.5 \mathrm{~mL} / \mathrm{min}$ was used as a carrier gas. The oven temperature was programmed with an initial hold at $100^{\circ} \mathrm{C}$ for $5 \mathrm{~min}$, then followed by an increase to $250^{\circ} \mathrm{C}$ at a rate of $25^{\circ} \mathrm{C} / \mathrm{min}$ and held for $1 \mathrm{~min}$ at 250 ${ }^{\circ} \mathrm{C}$, and finally increased to $290^{\circ} \mathrm{C}$ at a rate of $3{ }^{\circ} \mathrm{C} / \mathrm{min}$ and maintained at $290^{\circ} \mathrm{C}$ for $40 \mathrm{~min}$. The injector and detector temperatures were 270 and $300^{\circ} \mathrm{C}$, respectively. 


\subsection{Statistical analysis}

Statistical analysis was performed using Minitab® 16.1.1 software (Minitab Inc., State Collage, PA, USA). The results were expressed as the mean value \pm standard deviation. Data were statistically evaluated by analysis of variance (ANOVA) and followed by Tukey's multiple comparison test at a significance level of $p<.05$.

\section{Results and discussion}

Phytosterol impregnation mechanism mainly depended on the solubility of phytosterols in $\mathrm{SC}-\mathrm{CO}_{2}$ and textural properties of the NSA. Briefly, phytosterols were first dissolved in $\mathrm{SC}^{-\mathrm{CO}_{2}}$ and formed a phytosterol- SC$\mathrm{CO}_{2}$ solvato complex. Then, the solvato complex diffused into the nanopores of the NSA. As the temperature decreased from 90 to $25^{\circ} \mathrm{C}$ at a cooling rate of $10{ }^{\circ} \mathrm{C} / \mathrm{min}$, the solubility of the phytosterols in $\mathrm{SC}-\mathrm{CO}_{2}$ drastically decreased to nearly zero and led the precipitation of phytosterols. Nanoporous structure of the NSA matrix prevented the formation of well-ordered large phytosterol crystals. Finally, the system was depressurized to atmospheric conditions at $25^{\circ} \mathrm{C}$ from liquid $\mathrm{CO}_{2}$ which eliminated the extraction of phytosterols during depressurization due to the limited solubility of phytosterols in liquid $\mathrm{CO}_{2}$ (Ubeyitogullari \& Ciftci, 2017). The impregnation capacity of the PSNSA was $91.2 \pm 1.9 \mathrm{mg}$ phytosterols/g PS-NSA which was comparable to that reported for the same impregnation conditions in our previous studies (Ubeyitogullari \& Ciftci, 2017; Ubeyitogullari, Moreau, et al., 2018). PS-NSA is an excellent ingredient for both granola bars and pudding because of their pregelatinized starch content in the original formulation which makes the replacement of starch with the PS-NSA very convenient. Granola bar and pudding represent solid and aqueous soft foods, respectively. Granola bars and puddings are also good options in a healthy diet due to their low-calorie, low-fat, high fiber, mineral and vitamin content.

\subsection{Morphology}

Fig. 1 depicts the SEM images of crude phytosterols, empty NSA and PSNSA. The size of crude phytosterol crystals ranged between 15 and 110 $\mu \mathrm{m}$ (Fig. 1a). Empty NSA had an open porous network structure (Fig. 

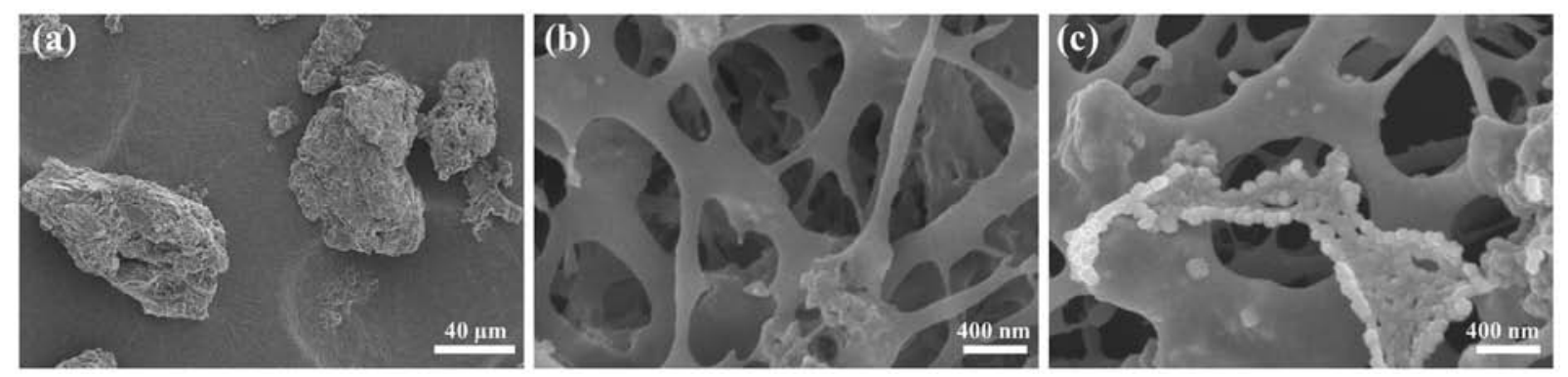

Fig. 1. SEM micrographs of (a) crude phytosterols, (b) empty NSA and (c) PS-NSA.

1b) similar to previously reported SEM images of wheat starch aerogels (Ubeyitogullari \& Ciftci, 2016a). Phytosterol nanoparticles in the PS-NSA were in spherical shape and their size was $65 \pm 8 \mathrm{~nm}$ (Fig. 1c); however, they tend to form aggregates rather than being isolated during the second and third impregnation cycles. Besides decreasing the size of phytosterols, this technique reduced the crystallinity of phytosterol particles (Ubeyitogullari \& Ciftci, 2016b, 2017; Ubeyitogullari, Moreau, et al., 2018), which in turn improves their water solubility due to higher lattice free energy (Babu \& Nangia, 2011).

Light microscopy images of the pudding formulations are presented in Fig. 2. Crude phytosterols were easily observed in the control pudding formulations prepared by pregelatinized starch (Fig. 2b) or empty NSA (Fig. 2c). The size of the crude phytosterols varied from 20 to 120 $\mu \mathrm{m}$ which is in agreement with the particle size of the crude phytosterols measured from SEM images. However, phytosterol particles were not clearly observed with the PS-NSA pudding formulation due to the nanosize of the particles (Fig. 2d). Micrograph of PS-NSA (Fig. 2d) was very similar to that of control prepared with pregelatinized starch without any phytosterol addition (Fig. 2a). Large crude phytosterol crystals in the control samples (Fig. 2b, c) were easily visible to the naked eye (data not shown) which might negatively affect the consumer acceptability.
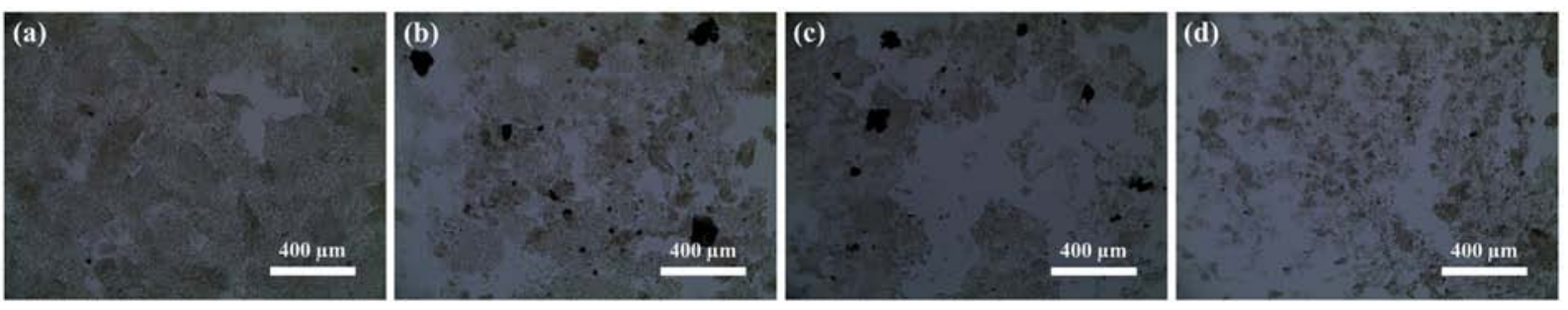

Fig. 2. Micrographs of (a) pregelatinized starch without any phytosterol addition, (b) crude PS+pregel starch, (c) crude PS+empty NSA and (d) PS-NSA pudding formulations. 
Table 3. Lipid content of granola bar formulations and their corresponding phytosterol contents without phytosterol supplementation.

\begin{tabular}{lll} 
Granola bar formulation & $\begin{array}{l}\text { Lipid content } \\
\text { (wt\%, wet basis) }\end{array}$ & $\begin{array}{l}\text { Phytosterol content } \\
(\mathrm{mg} / 100 \mathrm{~g})\end{array}$ \\
\hline Regular-fat & $23.8 \pm 0.3$ & $152.7 \pm 3.6$ \\
Low-fat & $7.0 \pm 0.2$ & $16.5 \pm 0.3$ \\
Non-fat & $0.1 \pm 0.0$ & $0.0 \pm 0.0$ \\
\hline
\end{tabular}

\subsection{Lipid and phytosterol content of the granola bar and pudding formulations}

Lipid contents of the granola bar formulations were determined (Table 3 ) as lipids might have a significant effect on the bioaccessibility of lipophilic bioactives (McClements et al., 2015). The regular-fat granola bar formulation had $24 \mathrm{wt} \%$ lipid content and this value decreased to 7 wt $\%$ when canola oil was excluded from the formulation to obtain a lowfat formulation. Furthermore, the efficacy of the phytosterol nanoparticles was investigated in a non-fat granola bars which were obtained by extraction of lipids from the ingredients before the granola bar preparation. Naturally occurring phytosterols in the granola bar ingredients, mainly, almonds, oats and shredded coconut, were determined and taken into account when bioaccessibility calculations were performed. Phytosterol content of the regular-fat granola bar ingredients was $153 \mathrm{mg} / 100$ $\mathrm{g}$ (Table 3) where the main source of the phytosterols was the canola oil in the formulation. $\beta$-sitosterol, campesterol and brassicasterol were the major phytosterols detected. Canola oil had a phytosterol content of $813 \mathrm{mg} / 100 \mathrm{~g}$ oil which agrees with the values previously reported in the literature (Ghazani, García- Llatas, \& Marangoni, 2013). Phytosterol content of the low-fat granola bar ingredients was as low as $17 \mathrm{mg} / 100$ $\mathrm{g}$ (Table 3). Non-fat granola bar ingredients did not have any phytosterols as they were extracted with the lipids during the defatting step. All the pudding formulations were non-fat by the nature of the ingredients used and the puddings did not have any naturally occurring phytosterols.

\subsection{Textural properties}

Hardness of the non-, low- and regular-fat granola bars is shown in Fig. 3. Hardness of the granola bars increased significantly when the lipid 


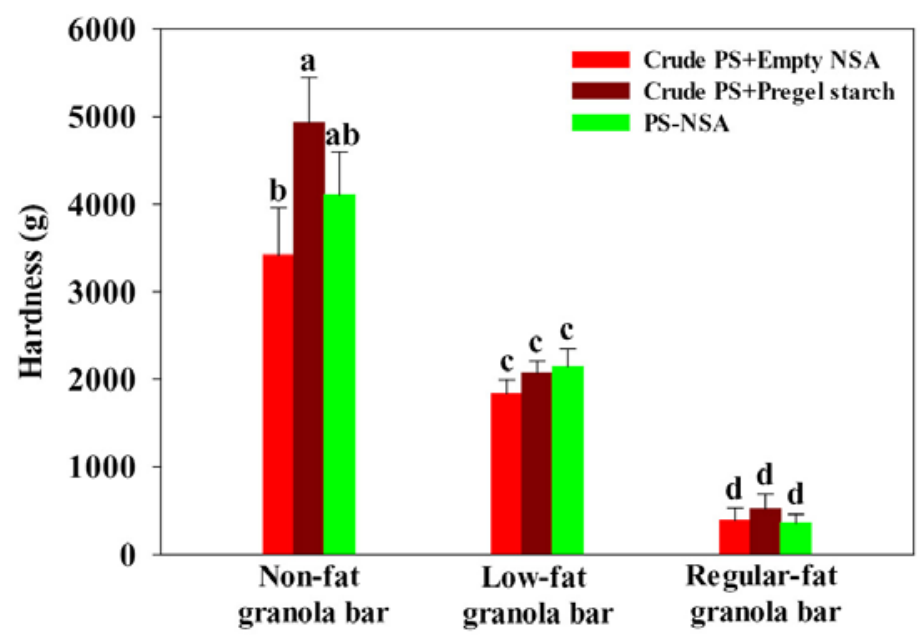

Fig. 3. Hardness of different granola bar formulations.

content decreased from 24 to $0 \mathrm{wt} \%(p<.05)$. There were no significant differences among the hardness of the samples (crude PS+empty NSA, crude PS+pregel starch, and PS-NSA) when low- or regular-fat granola formulations were used. Hardness of the low- and regular-fat granola bars ranged between 1839 and 2147 and 356-524 g, respectively. However, the hardness of the crude PS+empty NSA ( $3421 \mathrm{~g}$ ) was significantly lower than that of the other control prepared with pregelatinized starch (4936 g) when granola bars were formulated with non-fat ingredients (Fig. 3). The starch type (empty NSA vs pregelatinized starch) was the sole different ingredient in those non-fat granola bar control formulations. The physical properties of the NSA and pregelatinized starch could differ in terms of crystallinity, porosity, surface area and density (Ubeyitogullari, Brahma, Rose, \& Ciftci, 2018; Ubeyitogullari \& Ciftci, 2016a) which might affect the water solubility/water absorption and consequently alter the hardness.

A higher lipid content in the granola bar formulations could interfere with the interaction between the ingredients such as starch and water which might result in a decrease in hardness. Lipids might also act as a barrier for water migration and minimize the moisture lost during baking which leads to decreased hardness (Takeungwongtrakul \& Benjakul, 2017). Similar relationship between lipid content and hardness was found in the literature (Manohar \& Rao, 1999; Tarancón, Sanz, Salvador, \& Tárrega, 2014). For instance, Tarancón et al. (2014) investigated the effect of lipid content (10.6 and $15.6 \mathrm{wt} \%$ ) on the texture of the biscuits. When sunflower oil with xanthan gum was used as the fat, 
the hardness of the biscuits decreased from 3131 to $1693 \mathrm{~g}$ as the lipid content increased from 10.6 to 15.6 wt\% (Tarancón et al., 2014).

Instant puddings were formed by gelation of skim milk using gelling agent of tetrasodium pyrophosphate with gelation accelerator disodium phosphate (Mizuno \& Lucey, 2007). Table 4 summarizes the results of texture profile analysis of pudding formulations. Adhesiveness, springiness and cohesiveness of the puddings were not significantly different among the treatments ( $p>.05$ ) which means that the texture of the puddings was similar in terms of firmness and stickiness (Thaiudom \& Pracham, 2018). On the other hand, hardness and gumminess of the crude PS+empty NSA pudding were significantly lower than those of the other pudding formulations $(p<.05)$ (Table 4). Lower hardness suggests lower viscosity and runny texture (Moin, Ali, \& Hasnain, 2017) of the pudding prepared with the empty NSA. As mentioned above, NSA had different physical properties from the pregelatinized starch which might affect the gelling and consequently textural properties. PS-NSA was exposed to higher processing temperature (impregnation temperature of $90{ }^{\circ} \mathrm{C}$ ) than empty NSA (drying temperature of $40^{\circ} \mathrm{C}$ ). Hence, the pregelatinized starch in the PS-NSA might result in higher viscosity in the pudding compared to empty NSA due to the dry heat treatment at $90{ }^{\circ} \mathrm{C}$ (Lee, Yang, Chung, \& Lim, 2017). Although there was not an obvious impact of the crude phytosterols on the texture of the puddings, crude phytosterols were clearly observed in the matrix (Fig. 2b, c) which may impair sensory attributes and consumer acceptability. Crystalline structure of the crude phytosterols is known to lead to a gritty or sandy mouthfeel (Moreno-Calvo et al., 2014; Ubeyitogullari \& Ciftci, 2016b). Nevertheless, none of the instrumental parameters satisfactorily predicted the gritty mouthfeel of puddings (Henry, Katz, Pilgrim, \& May, 1971), snack bars (Kim et al., 2009) and cheese (Everard et al., 2006).

Table 4. Texture profile analysis parameters of pudding formulations.

\begin{tabular}{lccccc} 
Pudding formulation* & $\begin{array}{c}\text { Hardness } \\
(\mathrm{g})\end{array}$ & $\begin{array}{c}\text { Adhesiveness } \\
(\mathrm{g} . \mathrm{sec})\end{array}$ & Springiness & Cohesiveness & $\begin{array}{c}\text { Gumminess } \\
(\mathrm{g})\end{array}$ \\
\hline Crude PS+empty NSA & $73.9 \pm 1.3^{\mathrm{b}}$ & $-144.8 \pm 14.0^{\mathrm{a}}$ & $0.94 \pm 0.02^{\mathrm{a}}$ & $0.83 \pm 0.04 \mathrm{a}$ & $61.2 \pm 1.7^{\mathrm{b}}$ \\
Crude PS+pregel starch & $85.9 \pm 2.2^{\mathrm{a}}$ & $-156.9 \pm 19.3^{\mathrm{a}}$ & $0.97 \pm 0.02^{\mathrm{a}}$ & $0.82 \pm 0.04 \mathrm{a}$ & $70.1 \pm 1.4^{\mathrm{a}}$ \\
PS-NSA & $84.6 \pm 1.5^{\mathrm{a}}$ & $-185.5 \pm 13.3^{\mathrm{a}}$ & $0.95 \pm 0.01^{\mathrm{a}}$ & $0.86 \pm 0.02^{\mathrm{a}}$ & $72.6 \pm 0.2^{\mathrm{a}}$ \\
\hline
\end{tabular}

* Data are expressed as mean \pm standard deviation. Means in the same column with different superscript letters are significantly different $(p<.05)$. 


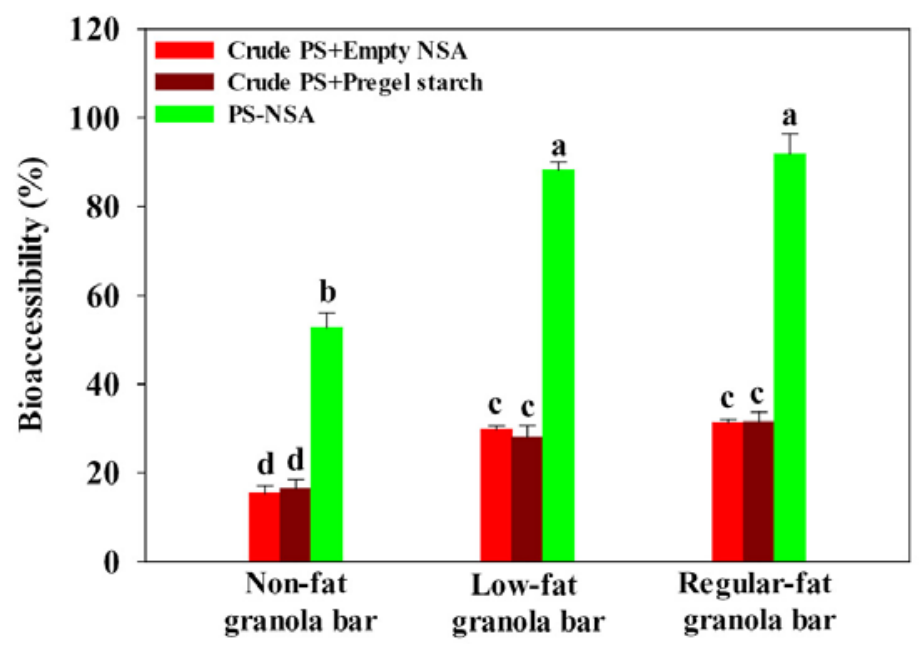

Fig. 4. Bioaccessibility of phytosterols in different granola bar formulations after simulated digestion.

\subsection{Bioaccessibility of phytosterols}

Bioaccessibility of the phytosterols in the granola bar formulations is depicted in Fig. 4. Both crude PS+empty NSA and crude PS+pregel starch formulations were investigated as controls in order to eliminate any effect of starch type on the bioaccessibility. The bioaccessibility of phytosterols was significantly enhanced with PS-NSA in all granola bar formulations $(p<.05)$. Regular- and low-fat granola bar formulations resulted in similar phytosterols' bioaccessibilities demonstrating the significant role of lipids on phytosterol bioaccessibility (Fig. 4). Bioaccessibility of crude phytosterols varied between 28.0 and 29.8 and $31.3-31.5 \%$ in low- and regular-fat granola bars, respectively. Low-crystallinity phytosterol nanoparticles (PS-NSA) showed significantly higher bioaccessibility $(p<.05)$; it was 88.2 and $91.8 \%$ for low- or regular-fat granola bars, respectively. Although lipid content has a major impact on the bioaccessibility of lipophilic bioactives owing to the effect on the solubilization in the mixed micelles (Alvarez-Sala et al., 2016; Kopec \& Failla, 2018; McClements, Zou, et al., 2015), decreasing the lipid content from 24 to 7 wt\% (Table 3) did not significantly alter the bioaccessibility of phytosterols. Lipids are involved in the solubilization of phytosterols into mixed micelles and formation of mixed micelles which stabilize the phytosterols in the bioaccessible fraction obtained after simulated digestion (McClements, Zou, et al., 2015). However, bile salts and phospholipids could 
be the limiting factors of the formation of micelles during simulated intestinal digestion in case of high lipid content (Mun, Kim, \& McClements, 2015) and may explain similar bioaccessibilities with regular- and lowfat granola bars. On the other hand, the bioaccessibility of phytosterols significantly decreased in all granola bar formulations when the samples were defatted $(p<.05)$ (Fig. 4). As the lipid content decreased from 7 to $0 \mathrm{wt} \%$, the bioaccessibility of the crude phytosterols decreased from ca. 30 to $16 \%$. Likewise, the bioaccessibility of the low-crystallinity phytosterol nanoparticles in non-fat granola bar decreased to $52.7 \%$. Those results suggest that there must be a threshold lipid content required to maximize the solubilization capacity of the mixed micelles. Similar effect of lipids on the bioaccessibility of phytosterols were observed by Alvarez-Sala et al. (2016). In that study, phytosterol-enriched milk-based fruit beverages with fat contents of 2.4 and $1.1 \%$ were prepared and phytosterols' bioaccessibilities were determined by a simulated digestion. The bioaccessibility of phytosterols in high-fat beverages (31.4\%) was much higher than in low-fat beverages (8.7\%) (Alvarez-Sala et al., 2016). Furthermore, Zhang et al. (2016) investigated the effect of lipid content of the excipient emulsions on the bioaccessibility of carotenoids in raw and cooked carrots. The increase in lipid content (from 0 to 8 wt\%) improved the bioaccessibility of carotenoids (from 8.1 to $44.6 \%$ for cooked carrots and from 0.93 to $26.2 \%$ for raw carrots) (Zhang et al., 2016). Furthermore, texture of the granola bars (Fig. 3) might have impacted the bioaccessibility of phytosterols (Fig. 4). Harder food matrix reduces the bioaccessibility of bioactives through restricting the action of the enzymes and liberation of the bioactives (McClements, Li, \& Xiao, 2015). Nonetheless, the effect of texture of the granola bar on the bioaccessibility was minimized by grinding (simulated mastication) prior to oral digestion.

Fig. 5 shows the bioaccessibility of phytosterols in the pudding formulations after a sequential oral, gastric and intestinal digestion. PSNSA had a significantly higher bioaccessibility (19.2\%) in the pudding formulations compared to crude PS+empty NSA (2.4\%) and crude PS+pregel starch pudding formulations (2.2\%) (Fig. 5). The new nanomanufacturing process improved the bioaccessibility of crude phytosterols by 8-folds in puddings due to the decrease in size and crystallinity of the phytosterols. The bioaccessibility of the phytosterols in the puddings rather than in the granola bars was more comparable to our previous study where the simulated digestion was carried out with just PS-NSA 


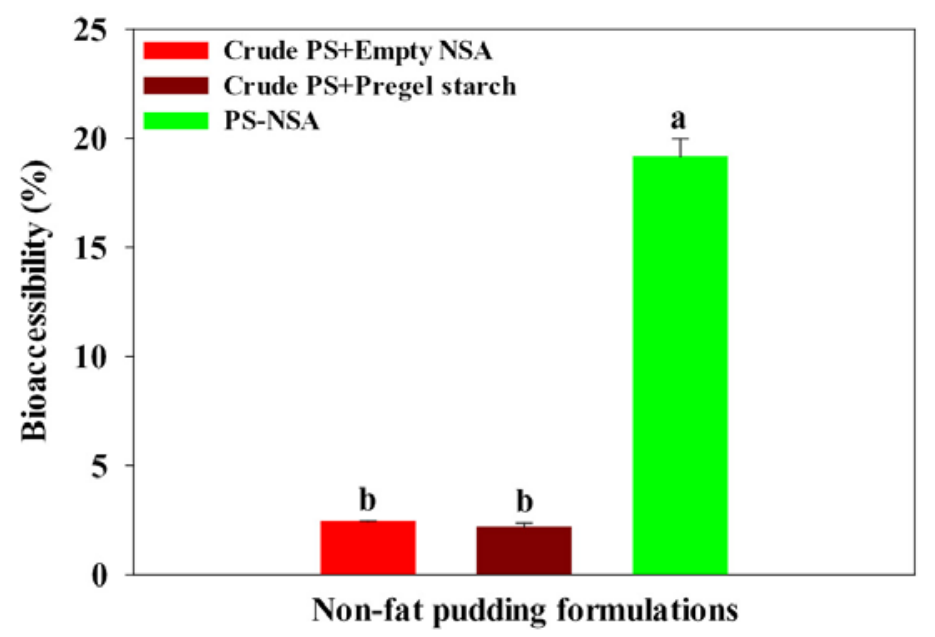

Fig. 5. Bioaccessibility of phytosterols in pudding formulations after simulated digestion.

(Ubeyitogullari, Moreau, et al., 2018). This was attributed to the simpler ingredients involved in the puddings compared to granola bars. Bioaccessibility of both crude phytosterols and low-crystallinity phytosterol nanoparticles in the granola bars was higher than in the puddings. Granola bar ingredients included more proteins and emulsifiers coming from oats, almonds, coconut, egg whites and gum arabic which might have improved the solubilization of phytosterols in the aqueous phase after simulated digestion. One explanation is that $\beta$-glucan, protein and bioactive peptides found in oats have emulsion stabilizing capacities (Gangopadhyay, Hossain, Rai, \& Brunton, 2015; Lazaridou \& Biliaderis, 2007). Similarly, egg white and coconut proteins exhibit improvements in the stability of emulsions and delivery of bioactives (Gu et al., 2017; Onsaard, Vittayanont, Srigam, \& McClements, 2005).

Comparing the bioaccessibility of phytosterols in different formulations is challenging due to the type of ingredients, food matrix and digestion procedure used. Depending on the beverage type used, the bioaccessibility of microencapsulated phytosterols in fruit-based milk beverages changed between 2.6 and 6.5\% (Alemany et al., 2013). Inclusion of phytosterols into fermented milk beverages improved the phytosterols' bioaccessibility up to $16 \%$ (Vaghini, Cilla, Garcia-Llatas, \& Lagarda, 2016). Both studies showed lower bioaccessibility of phytosterols than the granola bars investigated in this study whereas the bioaccessibility of crude phytosterols in puddings was lower due to the absence of lipids in the formulation. In another study, microencapsulated phytosterol-enriched 
dark chocolate, where the size of microencapsulated phytosterols added into dark chocolate ranged between 20 and $35 \mu \mathrm{m}$, resulted in lower bioaccessibilities of phytosterols (6.5-8.4\%) than PS-NSA both in granola bars (92\%) and puddings (19\%) (Tolve et al., 2018).

\section{Conclusions}

In this study, a new approach to forming low-crystallinity phytosterol nanoparticles was presented and the bioaccessibility of the novel phytosterol nanoparticles in real food systems was investigated. Bioaccessibility of phytosterols was significantly enhanced by incorporating them into NSAs in all the food formulations (non-, low-, and regular-fat granola bars, and puddings). Bioaccessibilities of 88 and $92 \%$ were achieved with low-crystallinity phytosterol nanoparticles when incorporated into low- and regular-fat granola bars, respectively. Bioaccessibility of crude phytosterols in low- and regular-fat granola bars was ca. 30\%. However, bioaccessibility of the crude phytosterols in the non-fat granola bars was ca. $16 \%$ and that was improved up to $53 \%$ by low-crystallinity phytosterol nanoparticles. PS-NSA in the pudding (19\%) showed significantly higher bioaccessibility than the crude phytosterols (2\%).

Results have shown that PS-NSA can increase the bioaccessibility of phytosterols in non-fat both dry solid and aqueous foods. This approach allows the incorporation of phytosterols into non-fat foods to develop health and wellness improving foods in a simple and clean manner. This is an alternative to emulsion formation or esterification methods which generate liquid or semisolid high-fat foods. PS-NSA has the potential to maximize the health benefits of phytosterols, and potentially other bioactives, in smaller doses.

Conflict of interest - The authors declare no conflict of interest.

Acknowledgments - This project is based on research that was supported by the Hatch Multistate Research capacity funding program (Accession Number 1011129) from the USDA National Institute of Food and Agriculture, ARD Innovation Fund for Wheat/Cereal Crops and the Wheat/Cereal Scholarship \& Fellowship Support Fund, and University of Nebraska Collaboration Initiative Seed Grant. This research was performed in part in the Nebraska Nanoscale Facility: National Nanotechnology Coordinated Infrastructure and Nebraska Center for Materials and Nanoscience, which are 
supported by the National Science Foundation under Award NNCI-1542182, and the Nebraska Research Initiative. Authors thank Dr. Devin Rose for the help in granola bar and pudding preparation.

\section{References}

Aigster, A., Duncan, S. E., Conforti, F. D., \& Barbeau, W. E. (2011). Physicochemical properties and sensory attributes of resistant starch-supplemented granola bars and cereals. LWT - Food Science and Technology, 44(10), 2159-2165. https://doi. org/10.1016/j.lwt.2011.07.018

Aldini, R., Micucci, M., Cevenini, M., Fato, R., Bergamini, C., Nanni, C., \& Budriesi, R. (2014). Anti-inflammatory effect of phytosterols in experimental murine colitis model: Prevention, induction, remission study. PLoS One, 9(9), e108112. https:// doi.org/10.1371/journal.pone.0108112

Alemany, L., Cilla, A., Garcia-Llatas, G., Rodriguez-Estrada, M. T., Cardenia, V., \& Alegría, A. (2013). Effect of simulated gastrointestinal digestion on plant sterols and their oxides in enriched beverages. Food Research International, 52(1), 1-7. https://doi.org/10.1016/j.foodres.2013.02.024

Alvarez-Sala, A., Garcia-Llatas, G., Cilla, A., Barberá, R., Sánchez-Siles, L. M., \& Lagarda, M. J. (2016). Impact of lipid components and emulsifiers on plant sterols bioaccessibility from milk-based fruit beverages. Journal of Agricultural and Food Chemistry, 64(28), 5686-5691. https://doi.org/10.1021/acs.jafc.6b02028

Babu, N. J., \& Nangia, A. (2011). Solubility advantage of amorphous drugs and pharmaceutical cocrystals. Crystal Growth \& Design, 11(7), 2662-2679. https:// doi.org/10.1021/cg200492w

Botelho, P. B., Galasso, M., Dias, V., Mandrioli, M., Lobato, L. P., Rodriguez-Estrada, M. T., \& Castro, I. A. (2014). Oxidative stability of functional phytosterol-enriched dark chocolate. LWT - Food Science and Technology, 55(2), 444-451. https://doi. org/10.1016/j.lwt.2013.09.002

Cao, W.-J., Ou, S.-Y., Lin, W.-F., \& Tang, C.-H. (2016). Food protein-based phytosterol nanoparticles: Fabrication and characterization. Food \& Function, 7(9), 39733980. https://doi.org/10.1039/C6F000861E

Comunian, T. A., Chaves, I. E., Thomazini, M., Moraes, I. C. F., Ferro-Furtado, R., de Castro, I. A., \& Favaro-Trindade, C. S. (2017). Development of functional yogurt containing free and encapsulated echium oil, phytosterol and sinapic acid. Food Chemistry, 237, 948-956. https://doi.org/10.1016/j.foodchem.2017.06.071

Demonty, I., Ras, R. T., van der Knaap, H. C. M., Duchateau, G. S. M. J. E., Meijer, L., Zock, P. L., ...Trautwein, E. A. (2009). Continuous dose-response relationship of the LDL-cholesterol-lowering effect of phytosterol intake. The Journal of Nutrition, 139(2), 271-284. doi: https://doi.org/10.3945/jn.108.095125

Di Battista, C. A., Constenla, D., Ramírez-Rigo, M. V., \& Piña, J. (2015). The use of arabic gum, maltodextrin and surfactants in the microencapsulation of phytosterols by spray drying. Powder Technology, 286, 193-201. https://doi. org/10.1016/j.powtec.2015.08.016 
EFSA (2012). Scientific opinion on the substantiation of a health claim related to $3 \mathrm{~g} /$ day plant sterols/stanols and lowering blood LDL-cholesterol and reduced risk of (coronary) heart disease pursuant to article 19 of regulation (EC) no 1924/2006. EFSA Journal, 10(5), 2693. https://doi.org/10.2903/j.efsa.2012.2693

Everard, C. D., O'Callaghan, D. J., Howard, T. V., O’Donnell, C. P., Sheehan, E. M., \& Delahunty, C. M. (2006). Relationships between sensory and rheological measurements of texture in maturing commercial cheddar cheese over a range of moisture and $\mathrm{pH}$ at the point of manufacture. Journal of Texture Studies, 37(4), 361-382. https://doi.org/10.1111/j.1745-4603.2006.00057.x

FDA (2000). Food labeling: Health claims; plant sterol/stanol esters and coronary heart disease; interim final rule. Retrieved April 28, from https://www.gpo.gov/ fdsys/pkg/FR-2000-09-08/pdf/00-22892.pdf

FDA (2010). Food labeling; health claim; phytosterols and risk of coronary heart disease. Retrieved April 28, 2018, from https://www.regulations.gov/ document?D=FDA-2000-P-0102-0006

Fisher, S., Wachtel, E. J., Aserin, A., \& Garti, N. (2013). Solubilization of simvastatin and phytosterols in a dilutable microemulsion system. Colloids and Surfaces B: Biointerfaces, 107, 35-42. https://doi.org/10.1016/i.colsurfb.2013.01.036

Folch, J., Lees, M., \& Stanley, G. H. S. (1957). A simple method for the isolation and purification of total lipides from animal tissues. Journal of Biological Chemistry, 226(1), 497-509.

Gangopadhyay, N., Hossain, M., Rai, D., \& Brunton, N. (2015). A review of extraction and analysis of bioactives in oat and barley and scope for use of novel food processing technologies. Molecules, 20(6), 10884.

Ghazani, S. M., García-Llatas, G., \& Marangoni, A. G. (2013). Minor constituents in canola oil processed by traditional and minimal refining methods. Journal of the American Oil Chemists' Society, 90(5), 743-756. https://doi.org/10.1007/ s11746-013-2215-2

Gu, L., Su, Y., Zhang, Z., Zheng, B., Zhang, R., McClements, D. J., \& Yang, Y. (2017). Modulation of lipid digestion profiles using filled egg white protein microgels. Journal of Agricultural and Food Chemistry, 65(32), 6919-6928. https://doi. org/10.1021/acs.jafc. 7 b02674

He, W.-S., Zhu, H., \& Chen, Z.-Y. (2018). Plant sterols: Chemical and enzymatic structural modifications and effects on their cholesterol-lowering activity. Journal of Agricultural and Food Chemistry, 66(12), 3047-3062. https://doi.org/10.1021/ acs.jafc.8b00059

Henry, W. F., Katz, M. H., Pilgrim, F. J., \& May, A. T. (1971). Texture of semi-solid foods: Sensory and physical correlates. Journal of Food Science, 36(1), 155-161. https:// doi.org/10.1111/j.1365-2621.1971.tb02059.x

Jalabert-Malbos, M.-L., Mishellany-Dutour, A., Woda, A., \& Peyron, M.-A. (2007). Particle size distribution in the food bolus after mastication of natural foods. Food Quality and Preference, 18(5), 803-812. https://doi.org/10.1016/j. foodqual.2007.01.010

Kawachi, H., Tanaka, R., Hirano, M., Igarashi, K., \& Ooshima, H. (2006). Crystallization of $\beta$-sitosterol using a water-immiscible solvent hexane. Journal of Chemical Engineering of Japan, 39(8), 869-875. https://doi.org/10.1252/icej.39.869 
Kim, E. H. J., Corrigan, V. K., Hedderley, D. I., Motoi, L., Wilson, A. J., \& Morgenstern, M. P. (2009). Predicting the sensory texture of cereal snack bars using instrumental measurements. Journal of Texture Studies, 40(4), 457-481. https://doi. org/10.1111/j.1745-4603.2009.00192.x

Kopec, R. E., \& Failla, M. L. (2018). Recent advances in the bioaccessibility and bioavailability of carotenoids and effects of other dietary lipophiles. Journal of Food Composition and Analysis, 68, 16-30. https://doi.org/10.1016/j. ifca.2017.06.008

Lazaridou, A., \& Biliaderis, C. G. (2007). Molecular aspects of cereal $\beta$-glucan functionality: Physical properties, technological applications and physiological effects. Journal of Cereal Science, 46(2), 101-118. https://doi.org/10.1016/j. jes.2007.05.003

Lee, S. J., Yang, Y. J., Chung, H. J., \& Lim, S. T. (2017). Effect of dry heating on physicochemical properties of pregelatinized rice starch. Cereal Chemistry, 94(6), 928-933. https://doi.org/10.1094/CCHEM-03-17-0045-R

Lin, Y., Knol, D., Menéndez-Carreño, M., Baris, R., Janssen, H.-G., \& Trautwein, E. A. (2018). Oxidation of sitosterol and campesterol in foods upon cooking with liquid margarines without and with added plant sterol esters. Food Chemistry, 241, 387396. https://doi.org/10.1016/j.foodchem.2017.08.118

López-García, G., Cilla, A., Barberá, R., \& Alegría, A. (2017). Protective effect of antioxidants contained in milk-based fruit beverages against sterol oxidation products. Journal of Functional Foods, 30, 81-89. https://doi.org/10.1016/j. jff.2016.12.028

Manohar, R. S., \& Rao, P. H. (1999). Effect of emulsifiers, fat level and type on the rheological characteristics of biscuit dough and quality of biscuits. Journal of the Science of Food and Agriculture, 79(10), 1223-1231. https://doi.org/10.1002/ (SICI)1097-0010(19990715)79:10<1223::AID-JSFA346>3.0.CO;2-W

McClements, D. J., Li, F., \& Xiao, H. (2015). The nutraceutical bioavailability classification scheme: Classifying nutraceuticals according to factors limiting their oral bioavailability. Annual Review of Food Science and Technology, 6(1), 299-327. https://doi.org/10.1146/annurev-food-032814-014043

McClements, D. J., Zou, L., Zhang, R., Salvia-Trujillo, L., Kumosani, T., \& Xiao, H. (2015). Enhancing nutraceutical performance using excipient foods: Designing food structures and compositions to increase bioavailability. Comprehensive Reviews in Food Science and Food Safety, 14(6), 824-847. https://doi. org/10.1111/1541-4337.12170

Minekus, M., Alminger, M., Alvito, P., Ballance, S., Bohn, T., Bourlieu, C., \& Brodkorb, A. (2014). A standardised static in vitro digestion method suitable for food An international consensus. Food \& Function, 5(6), 1113-1124. https://doi. org/10.1039/C3F060702I

Mizuno, R., \& Lucey, J. A. (2007). Properties of milk protein gels formed by phosphates. Journal of Dairy Science, 90(10), 4524-4531. https://doi. org/10.3168/jds.2007-0229

Moin, A., Ali, T. M., \& Hasnain, A. (2017). Characterization and utilization of hydroxypropylated rice starches for improving textural and storage properties of 
rice puddings. International Journal of Biological Macromolecules, 105, 843-851. https://doi.org/10.1016/j.ijbiomac.2017.07.109

Moreno-Calvo, E., Temelli, F., Cordoba, A., Masciocchi, N., Veciana, J., \& Ventosa, N. (2014). A new microcrystalline phytosterol polymorph generated using C02-expanded solvents. Crystal Growth \& Design, 14(1), 58-68. https://doi. org/10.1021/cg401068n

Mun, S., Kim, Y.-R., \& McClements, D. J. (2015). Control of $\beta$-carotene bioaccessibility using starch-based filled hydrogels. Food Chemistry, 173, 454-461. https://doi. org/10.1016/j.foodchem.2014.10.053

Ningtyas, D. W., Bhandari, B., Bansal, N., \& Prakash, S. (2018). Texture and lubrication properties of functional cream cheese: Effect of $\beta$-glucan and phytosterol. Journal of Texture Studies, 49(1), 11-22. https://doi.org/10.1111/jtxs.12282

Onsaard, E., Vittayanont, M., Srigam, S., \& McClements, D. J. (2005). Properties and stability of oil-in-water emulsions stabilized by coconut skim milk proteins. Journal of Agricultural and Food Chemistry, 53(14), 5747-5753. https://doi. org/10.1021/jf050312r

Panpipat, W., Chaijan, M., \& Guo, Z. (2018). Oxidative stability of margarine enriched with different structures of $\beta$-sitosteryl esters during storage. Food Bioscience, 22, 78-84. https://doi.org/10.1016/j.fbio.2018.01.009

Ras, R. T., Geleijnse, J. M., \& Trautwein, E. A. (2014). LDL-cholesterol-lowering effect of plant sterols and stanols across different dose ranges: A meta-analysis of randomised controlled studies. The British Journal of Nutrition, 112(2), 214-219. https://doi.org/10.1017/S0007114514000750

Rossi, L., Seijen ten Hoorn, J. W. M., Melnikov, S. M., \& Velikov, K. P. (2010). Colloidal phytosterols: Synthesis, characterization and bioaccessibility. Soft Matter, 6(5), https://doi.org/10.1039/b911371a 928-928

Rudzińska, M., Przybylski, R., \& Wąsowicz, E. (2014). Degradation of phytosterols during storage of enriched margarines. Food Chemistry, 142, 294-298. https:// doi.org/10.1016/i.foodchem.2013.07.041

Rysz, J., Franczyk, B., Olszewski, R., Banach, M., \& Gluba-Brzozka, A. (2017). The use of plant sterols and stanols as lipid-lowering agents in cardiovascular disease. Current Pharmaceutical Design, 23(17), 2488-2495. https://doi.org/10.2174/13 81612823666170316112344

Shahzad, N., Khan, W., Md, S., Ali, A., Saluja, S. S., Sharma, S., ... Al-Ghamdi, S. S. (2017). Phytosterols as a natural anticancer agent: Current status and future perspective. Biomedicine \& Pharmacotherapy, 88, 786-794. https://doi.org/10.1016/j. biopha.2017.01.068 Supplement C.

Takeungwongtrakul, S., \& Benjakul, S. (2017). Biscuits fortified with microencapsulated shrimp oil: Characteristics and storage stability. Journal of Food Science and Technology, 54(5), 1126-1136. https://doi.org/10.1007/ $\underline{\text { s13197-017-2545-4 }}$

Tarancón, P., Sanz, T., Salvador, A., \& Tárrega, A. (2014). Effect of fat on mechanical and acoustical properties of biscuits related to texture properties perceived by consumers. Food and Bioprocess Technology, 7(6), 1725-1735. https://doi. org/10.1007/s11947-013-1155-z 
Thaiudom, S., \& Pracham, S. (2018). The influence of rice protein content and mixed stabilizers on textural and rheological properties of jasmine rice pudding. Food Hydrocolloids, 76, 204-215. https://doi.org/10.1016/j.foodhyd.2016.11.027

Tolve, R., Condelli, N., Can, A., \& Tchuenbou-Magaia, F. L. (2018). Development and characterization of phytosterol-enriched oil microcapsules for foodstuff application. Food and Bioprocess Technology, 11(1), 152-163. https://doi. org/10.1007/s11947-017-1990-4

Tolve, R., Condelli, N., Caruso, M. C., Barletta, D., Favati, F., \& Galgano, F. (2018). Fortification of dark chocolate with microencapsulated phytosterols: Chemical and sensory evaluation. Food \& Function, 9(2), 1265-1273. https://doi. org/10.1039/C7F001822C

Türk, M., \& Lietzow, R. (2004). Stabilized nanoparticles of phytosterol by rapid expansion from supercritical solution into aqueous solution. AAPS PharmSciTech, 5(4), e56. https://doi.org/10.1208/pt050456

Türk, M., \& Lietzow, R. (2008). Formation and stabilization of submicron particles via rapid expansion processes. Journal of Supercritical Fluids, 45(3), 346-355. https://doi.org/10.1016/j.supflu.2008.01.019

Türk, M., Upper, G., \& Hils, P. (2006). Formation of composite drug-polymer particles by co-precipitation during the rapid expansion of supercritical fluids. The Journal of Supercritical Fluids, 39(2), 253-263. https://doi.org/10.1016/j. supflu.2006.04.004

Ubeyitogullari, A., Brahma, S., Rose, D. J., \& Ciftci, O. N. (2018). In vitro digestibility of nanoporous wheat starch aerogels. Journal of Agricultural and Food Chemistry, 66(36), 9490-9497. https://doi.org/10.1021/acs.jafc.8b03231

Ubeyitogullari, A., \& Ciftci, O. N. (2016a). Formation of nanoporous aerogels from wheat starch. Carbohydrate Polymers, 147, 125-132. https://doi.org/10.1016/j. carbpol.2016.03.086

Ubeyitogullari, A., \& Ciftci, O. N. (2016b). Phytosterol nanoparticles with reduced crystallinity generated using nanoporous starch aerogels. RSC Advances, 6(110), 108319-108327. https://doi.org/10.1039/C6RA20675A

Ubeyitogullari, A., \& Ciftci, O. N. (2017). Generating phytosterol nanoparticles in nanoporous bioaerogels via supercritical carbon dioxide impregnation: Effect of impregnation conditions. Journal of Food Engineering, 207, 99-107. https://doi. org/10.1016/i.jfoodeng.2017.03.022

Ubeyitogullari, A., Moreau, R., Rose, D. J., Zhang, J., \& Ciftci, O. N. (2018). Enhancing the bioaccessibility of phytosterols using nanoporous corn and wheat starch bioaerogels. European Journal of Lipid Science and Technology, 1700229. https:// doi.org/10.1002/ejlt.201700229

Uddin, M. S., Sarker, M. Z. I., Ferdosh, S., Akanda, M. J. H., Easmin, M. S., Bt Shamsudin, S. H., \& Yunus, K. B. (2014). Phytosterols and their extraction from various plant matrices using supercritical carbon dioxide: A review. Journal of the Science of Food and Agriculture, 95(7), 1385-1394. https://doi.org/10.1002/jsfa.6833

Vaghini, S., Cilla, A., Garcia-Llatas, G., \& Lagarda, M. J. (2016). Bioaccessibility study of plant sterol-enriched fermented milks. Food \& Function, 7(1), 110-117. https:// doi.org/10.1039/C5F000458F 
Woyengo, T. A., Ramprasath, V. R., \& Jones, P. J. H. (2009). Anticancer effects of phytosterols. European Journal of Clinical Nutrition, 63(7), 813-820.

Zhang, R., Zhang, Z., Zou, L., Xiao, H., Zhang, G., Decker, E. A., \& McClements, D. J. (2016). Impact of lipid content on the ability of excipient emulsions to increase carotenoid bioaccessibility from natural sources (raw and cooked carrots). Food Biophysics, 11(1), 71-80. https://doi.org/10.1007/s11483-015-9418-z

Zychowski, L. M., Logan, A., Augustin, M. A., Kelly, A. L., Zabara, A., O’Mahony, J. A., \& Auty, M. A. E. (2016). Effect of phytosterols on the crystallization behavior of oilin-water milk fat emulsions. Journal of Agricultural and Food Chemistry, 64(34), 6546-6554. https://doi.org/10.1021/acs.jafc.6b01722 